\title{
DNA markers for differentiating isolates of Paecilomyces lilacinus
}

\author{
Myrian S. Tigano-Milani, ${ }^{1}$ Robert A. Samson, ${ }^{2}$ Irene Martins' \\ and Bruno W. S. Sobral ${ }^{3}$
}

\begin{abstract}
Author for correspondence: Bruno W. S. Sobral. Tel: +1 6195355491 or 5483. Fax: +1 6195355472.
\end{abstract} e-mail: sobral@lifsci.sdsu.edu or brunosfly@aol.com

\author{
1 Centro Nacional de \\ Recursos Genéticos e \\ Biotecnologia \\ (CENARGEN)/Empresa \\ Brasileira de Pesquisa \\ Agropecuária (EMBRAPA), \\ C.P. 02372, Brasilia, DF, \\ 70849-970, Brazil \\ 2 Centraalbureau voor \\ Schimmelcultures, PO Box \\ 273, NL-3740 AG Baarn, \\ The Netherlands \\ 3 California Institute of \\ Biological Research (CIBR), \\ 11099 N. Torrey Pines \\ Road, Suite 300, La Jolla, \\ CA 92037, USA
}

\begin{abstract}
Paecilomyces lilacinus is an agent for the potential biological control of soil nematodes. Arbitrarily primed PCR was used to fingerprint the genomes of 28 isolates of this fungus. Most (72\%) of the isolates originated from soil of different regions of Brazil. Fourteen 10-mer oligonucleotide primers of arbitrary sequence revealed 293 scorable binary characters. Distinct genotypes were obtained for each isolate. Cluster analysis showed a high level of variability among these genotypes. The similarity among pairwise comparisons of the isolates varied from $84.3 \%$ to $7.6 \%$, with a mean of $63.5 \%$. No clearly defined phenetic groups were identified by cluster or multivariate analyses. No correlation with geographical origin or host was detected. In addition, PCR with four pairs of consensus tRNA gene primers was performed on a subsample of $12 P$. Iilacinus isolates, three $P$. farinosus isolates, two $P$. fumosoroseus isolates, and one isolate of $P$. amoenoroseus. An inferred phylogeny based on 112 binary characters obtained by tRNA-PCR showed a monophyletic group which contained most of the P. Iilacinus isolates. In contrast, three isolates of $P$. farinosus were not in a monophyletic group under the inferred phylogeny. These results suggest that tRNA fingerprinting could provide a valuable tool which could be used to develop the molecular taxonomy of Paecilomyces, as morphological characteristics of asexual structures cannot entirely resolve species.
\end{abstract}

Keywords: biological control, phylogenetics, phenetics, arbitrarily primed PCR, tRNA fingerprinting

\section{INTRODUCTION}

Paecilomyces lilacinus is a typically soil-borne hyphomycete that has been isolated in different parts of the world, especially in warmer regions (Domsch \& Gams, 1980). $P$. lilacinus has remarkable versatility and can survive on diverse substrates and infect different hosts (Samson, 1974). It can live as a mycoparasite that colonizes sclerotia of several species of fungi (Gupta et al., 1993). Also, it has been reported to infect eggs and cysts of nematodes (Carneiro, 1992). Although the activity of P. lilacinus on insects is infrequently reported, there is one report of the use of this fungus to control populations of Nilaparvata lugens in rice fields (Rombach et al., 1986). Recently, an isolate of $P$. lilacinus has been studied as a potential biological agent to control eggs of both the nematode Meloidogyne javanica and the corn root worm, Diabrotica speciosa, in Brazil (Tigano-Milani et al., unpublished data).
$P$. lilacinus was the most frequently isolated species, when a survey of selective isolation of entomopathogenic fungi was conducted on soil samples from different regions of Brazil (Chase et al., 1986; Tigano-Milani et al., 1993). To study the efficacy of this potential biopesticide, it will be necessary to characterize the apparently large endemic, soil-borne population. Environmental release will also require means for positive identification of strains. Genetic markers can be used to study populations of $P$. lilacinus. Markers will be required to evaluate the efficacy of treatments, to study population dynamics and to allow characterization of genetic variation in $P$. lilacinus. Until now, $P$. lilacinus has been characterized mainly by virulence tests or biochemical characters (Samson, 1974; Carneiro, 1992). However, it is difficult to associate variability of these phenotypic characteristics with overall genetic and phylogenetic relationships. Isozyme markers, using 11 polymorphic systems, revealed little difference 
Table 1. Origin of Paecilomyces isolates

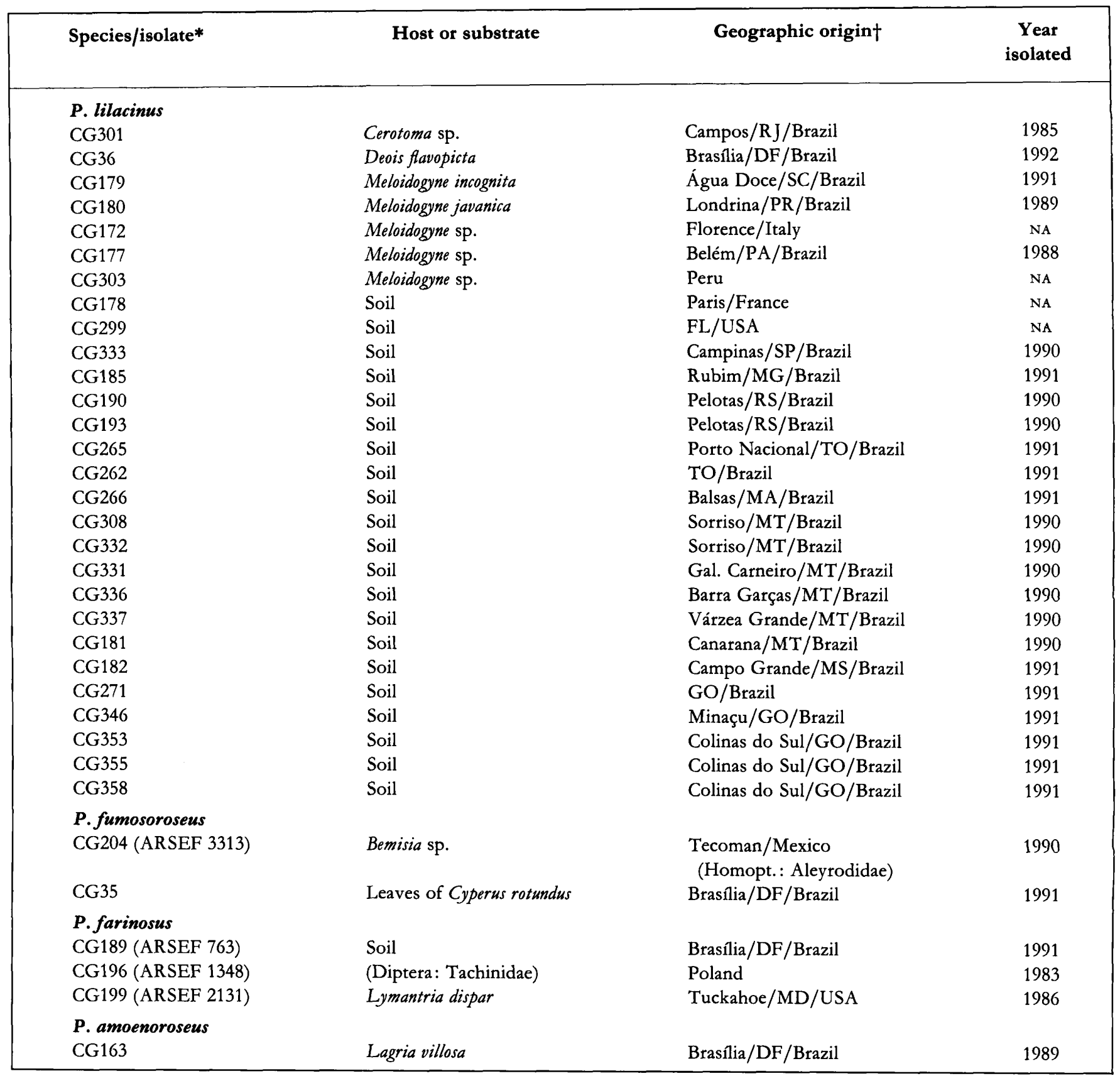

NA, Not available.

*CG, CENARGEN/EMBRAPA Collection, Brasilia, DF, Brazil; ARSEF, Agricultural Research Service Entomopathogenic Fungus Collection, USDA, Ithaca, NY, USA.

† Abbreviations refer to Brazilian states: DF, Federal district; SC, Santa Catarina; RJ, Rio de Janeiro; PR, Paraná; PA, Pará; SP, São Paulo; MG, Minas Gerais; MT, Mato Grosso; RS, Rio Grande do Sul; TO, Tocantins; MA, Maranhão; GO, Goiás.

among strains of $P$. lilacinus isolated from different geographical areas and diverse substrates (M. S. TiganoMilani and others, unpublished data). DNA markers provide more detailed genomic information than do isozymes (Sobral \& Honeycutt, 1994). PCR-based DNA markers, such as those generated by arbitrarily primed PCR (Welsh \& McClelland, 1990), have been extensively used in fingerprinting of various micro-organisms (Guthrie et al., 1992; Lehmann et al., 1992; Welsh et al., 1992), in particular some entomopathogenic fungi (Fegan et al., 1993; Bidochka et al., 1994; Tigano-Milani et al., 1994; M. S. Tigano-Milani and others, unpublished data), and plants (reviewed by Sobral \& Honeycutt, 1994). Arbitrarily primed PCR markers, also known as random 
Table 2. Marker performance of arbitrarily primed PCR and tRNA-PCR

\begin{tabular}{|lcc|}
\hline & AP-PCR & tRNA-PCR \\
\hline Primers screened & 46 & NA \\
Primers* (or pairs) used & 14 & 4 \\
for fingerprinting & & \\
Isolates analysed & 29 & 18 \\
Scorable characters & 293 & 112 \\
Characters scored/primer & $20 \cdot 9$ & 28 \\
(or pair) & & \\
\hline
\end{tabular}

NA, Not applicable.

* 10-mer primers: OPA-03, OPA-04, OPB-04, OPB-05, OPB-06, OPB-07, OPB-08, OPB-09, OPB-18, OPC-19, OPD-07, OPD-13, OPD-18 and OPU-06.

amplified polymorphic DNA (RAPD) markers (Williams et al., 1900) provide various advantages for the study of poorly characterized organisms. Most significantly, no DNA sequence information from the organism in question is needed (Welsh \& McClelland, 1990; Sobral \& Honeycutt, 1993, 1994). Arbitrarily primed PCR is rapid, relatively easy to perform, inherently amenable to automation, and reproducible (Sobral \& Honeycutt, 1993, 1994).

Specific PCR across variable regions, interspersed within highly conserved sequences, e.g. rRNA and tRNA genes, can be used to differentiate related species, at higher taxonomic levels than arbitrarily primed PCR. PCR amplification using consensus primers derived from tRNA gene sequences is a useful tool for differentiating micro-organisms at the species level and, in general, to improve the molecular systematics of bacteria and fungi (Welsh \& McClelland, 1991; McClelland et al., 1992; Tigano-Milani et al., 1994a,b; M. S. Tigano-Milani and others, unpublished data). Therefore, arbitrarily primed PCR can be used for population-level studies, whereas PCR with tRNA consensus primers can be used for interspecific and perhaps in some cases intergeneric comparisons; together, they provide fundamental tools for genetic and phylogenetic characterization of poorly studied organisms, such as entomopathogenic fungi. This study reports the use of arbitrarily primed PCR and tRNA-PCR using consensus primers to analyse the genetic variability among primarily Brazilian $P$. lilacinus isolates from insects, nematodes or soil.

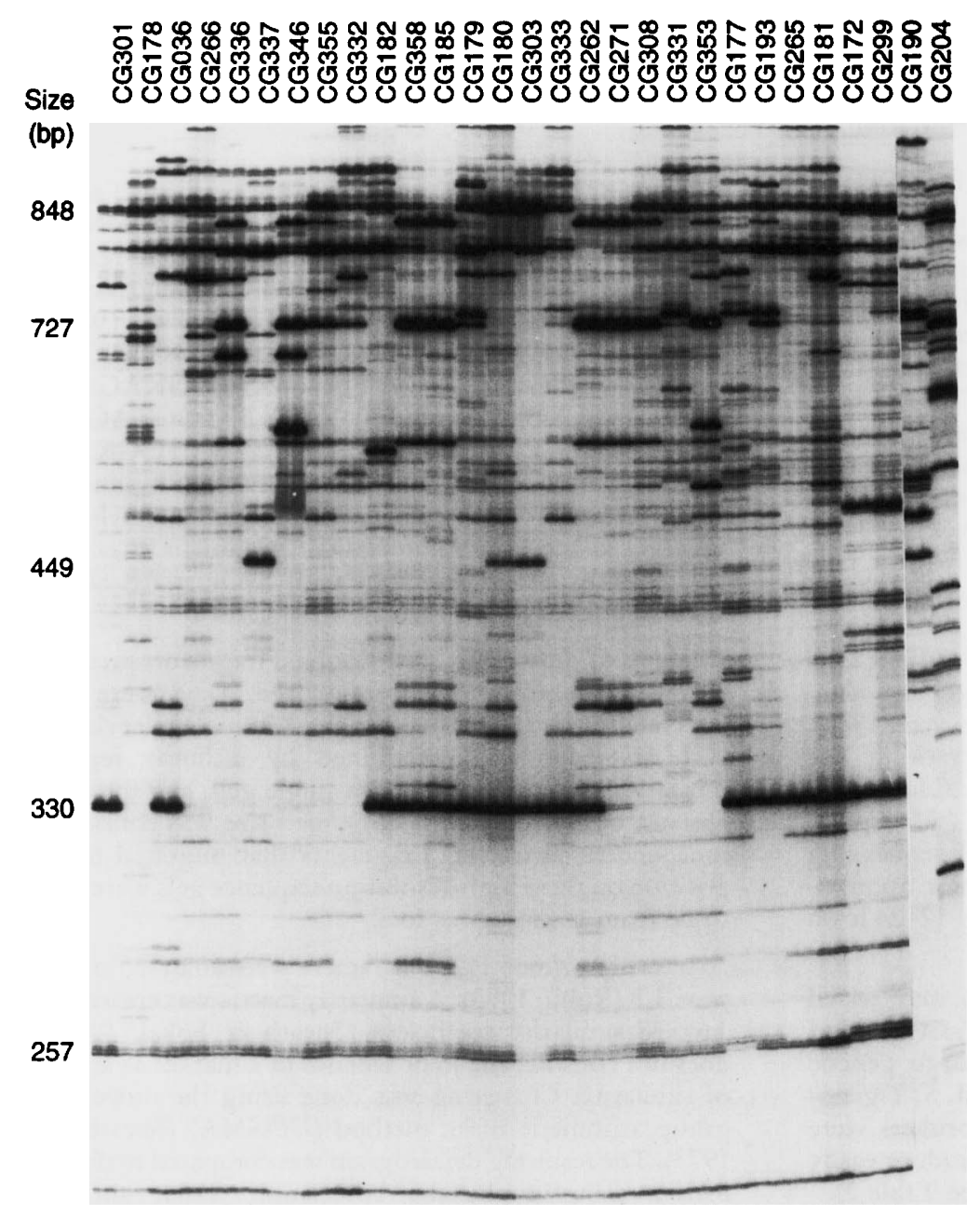

Fig. 1. Autoradiogram of a high-resolution, denaturing polyacrylamide gel showing typical results from arbitrarily primed PCR fingerprinting of Paecilomyces lilacinus isolates. Each strain appears in duplicate, with the first lane representing $10 \mathrm{ng}$ and the second $30 \mathrm{ng}$ of template DNA. The primer used was OPC-19. 


\section{METHODS}

Fungal cultures. Paecilomyces spp. isolates and their origins are listed in Table 1. Isolates were grown in $9 \mathrm{~cm}$ Petri dishes on $2 \%(\mathrm{w} / \mathrm{v})$ malt extract and oatmeal agar and incubated at $25^{\circ} \mathrm{C}$ in the dark. After $7 \mathrm{~d}$ the cultures were prepared for microscopic examination and morphological identification. Cultures which showed poor or no sporulation were further incubated at room temperature under diffuse daylight. Microscope slides were mounted in $60 \%(\mathrm{w} / \mathrm{v})$ lactic acid. Monoconidial cultures were produced for each isolate and maintained on Sabouraud dextrose agar with yeast extract ( $40 \mathrm{~g}$ dextrose, $10 \mathrm{~g}$ mycological peptone, $10 \mathrm{~g}$ agar in $1000 \mathrm{ml}$ distilled water, $\mathrm{pH} 5.6)$ at $25^{\circ} \mathrm{C}$. Mycelia were obtained from submerged cultures of spores incubated in Sabouraud dextrose broth with shaking at 150 r.p.m. at $25^{\circ} \mathrm{C}$ for $3 \mathrm{~d}$. Mycelia were harvested by filtration (Whatman no. 1), and stored at $-80^{\circ} \mathrm{C}$.

DNA extraction. Genomic DNA was extracted from lyophilized mycelia. Approximately $25 \mathrm{mg}$ of biomass were ground to a powder in a $1.5 \mathrm{ml}$ microfuge tube with a sterile toothpick. The powder was suspended in $500 \mu \mathrm{l}$ sterile lysis buffer $(50 \mathrm{mM}$ Tris/ $\mathrm{HCl}, 150 \mathrm{mM} \mathrm{NaCl}, 100 \mathrm{mM}$ EDTA), then $50 \mu \mathrm{l} 10 \%$ (w/v) SDS was added, and the tubes were gently shaken. After $1 \mathrm{~h}$ at $37^{\circ} \mathrm{C}, 75 \mu \mathrm{l} 5 \mathrm{M} \mathrm{NaCl}$ was added and mixed, then $60 \mu \mathrm{l}$ cetyltrimethylammonium bromide (CTAB) solution $(10 \%$, $w / v, C T A B$ in $7 \mathrm{M} \mathrm{NaCl}$ ) was added, mixed and the suspension was incubated at $65^{\circ} \mathrm{C}$ for $20 \mathrm{~min}$. The supernatant was extracted with an equal volume of chloroform/isoamyl alcohol $(24: 1, \mathrm{v} / \mathrm{v})$, treated with $5 \mu \mathrm{l} \mathrm{RNase}\left(10 \mathrm{mg} \mathrm{m}^{-1}\right)$ for $30 \mathrm{~min}$ at $37^{\circ} \mathrm{C}$, then $0.6 \mathrm{vol}$. 2-propanol was added to precipitate the nucleic acid. The pellets were washed with $70 \%(\mathrm{v} / \mathrm{v})$ ethanol, dried, and resuspended in water. The DNA was quantified fluorometrically and verified by agarose gel electrophoresis against a standard of similar size and known concentration.

Arbitrarily primed PCR. The PCR reactions were performed in $30 \mu \mathrm{l}$ volumes, using a System 9600 cycler (Perkin-Elmer). Two concentrations of each template DNA (10 and $30 \mathrm{ng}$ per reaction) were used to test reproducibility and eliminate sporadic amplification products from the analysis. Amplifications were performed using the following reaction mix: $4.0 \mathrm{mM} \mathrm{MgCl}$, $0.1 \mathrm{mM}$ of each dNTP (Pharmacia), $1 \mu \mathrm{Ci}$ $(37 \mathrm{kBq})$ of $\left[\alpha_{-}{ }^{32} \mathrm{P}\right] \mathrm{dCTP} \quad\left[3000 \mathrm{mCi} \mathrm{mmol}^{-1} \quad(11 \cdot 1 \mathrm{GBq}\right.$ $\mathrm{mmol}^{-1}$ ), NEN], $1 \mu \mathrm{M}$ primer, $2 \mathrm{U}$ AmpliTaq Stoffel fragment (Perkin-Elmer) (Sobral \& Honeycutt, 1993), and $1 \times$ the polymerase's recommended buffer. The temperature profile for all reactions was $94^{\circ} \mathrm{C}$ for $3 \mathrm{~min}$, followed by 40 cycles of $94^{\circ} \mathrm{C}$ for $1 \mathrm{~min}, 35^{\circ} \mathrm{C}$ for $1 \mathrm{~min}, 72{ }^{\circ} \mathrm{C}$ for $2.5 \mathrm{~min}$, with a final extension at $72^{\circ} \mathrm{C}$ for $7 \mathrm{~min}$ (Sobral \& Honeycutt, 1993). Amplification products were maintained at $15^{\circ} \mathrm{C}$ until electrophoresis. Reaction products were checked by loading $24 \mu \mathrm{l}$ onto a $2 \%$ Tris/borate/EDTA (TBE) agarose gel and visualized by staining with ethidium bromide (Maniatis et al., 1982). The remaining $6 \mu \mathrm{l}$ were added to $10 \mu \mathrm{l}$ of tracking dye containing $80 \%(\mathrm{v} / \mathrm{v})$ formamide, denatured at $65^{\circ} \mathrm{C}$ for $5 \mathrm{~min}$, then $2 \mu \mathrm{l}$ of each sample was loaded on a $4 \%(\mathrm{w} / \mathrm{v})$ polyacrylamide $/ 50 \%(\mathrm{w} / \mathrm{v})$ urea gel (a standard DNA sequencing gel). Electrophoresis was performed at $1500 \mathrm{~V}$ for approximately $4 \mathrm{~h}$. The gel was dried, then exposed for 12-24 h on X-Omat X-ray film (Kodak).

Forty-six 10-mer primers (Operon Technologies) were tested on a set of four $P$. lilacinus isolates, CG36, CG177, CG332 and CG299, which were selected because of their large genetic distances as calculated from isozyme phenotypes (M. S. TiganoMilani and others, unpublished data). Fourteen primers were selected for this study, based on their ability to produce easily distinguishable polymorphic fragment patterns (see Table 2).

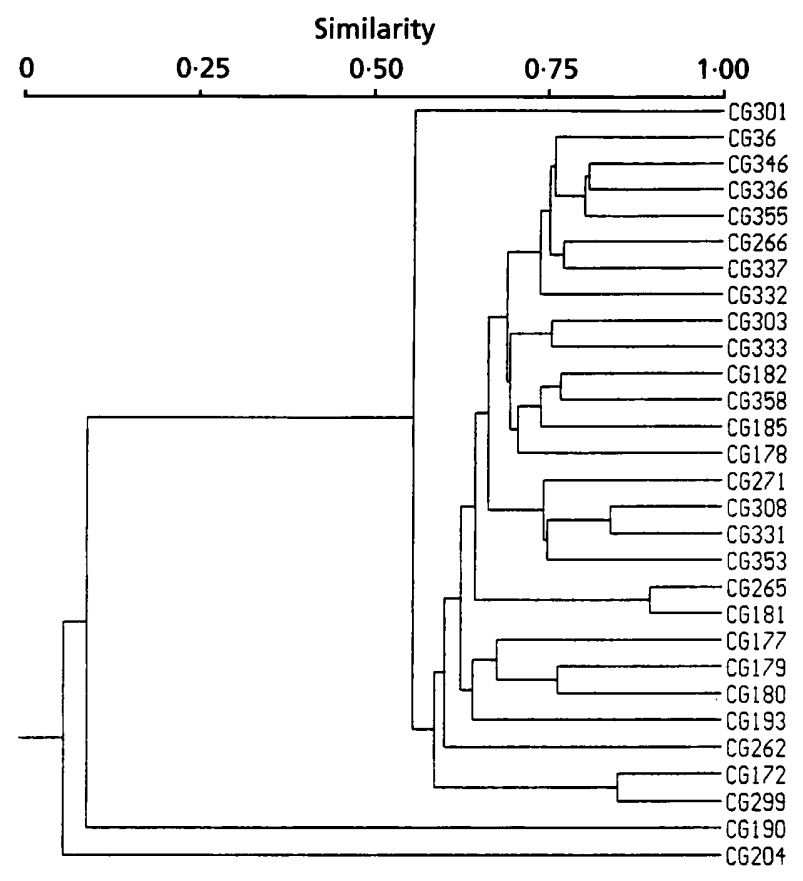

Fig. 2. Dendrogram constructed from arbitrarily primed $P C R$ data indicating relationships among Paecilomyces lilacinus isolates. A similarity matrix was calculated based on Jaccard coefficient. The tree was generated from the similarity matrix by unweighted pair group method, arithmetic mean (UPGMA). The correlation between the dendrogram and similarity matrix was 0.985 .

tRNA-PCR. $t$ RNA-PCR reactions were performed according to Welsh \& McClelland (1991). Two template DNA concentrations were used: 15 and $30 \mathrm{ng}$ per $30 \mu \mathrm{l}$ reaction. The following primers were synthesized by Genosys: T5A: $5^{\prime}$ AGTCCGGTGCTCTAACCAACTGAG-3' (Welsh \& McClelland, 1991); T3B: 5'-AGGTCGCGGGTTCGAATCC3' (McClelland et al., 1992); FEU: 5'-TTGGKAGAGCRWYRGACTGAA-3' (this study); YEU : 5'-TGGTAGARCRSMGGTCTCCA-3' (this study); AEU: 5'-GYTGGKAGAGCRCCTGCYTTG $-3^{\prime}$ (this study). The resulting amplified products were resolved by electrophoresis through $5 \%$ acrylamide $/ 50 \%$ urea gel in $1 \times$ Tris/borate/EDTA (Maniatis et al., 1982) and visualized by autoradiography with X-Omat AR film (Kodak) with an intensifying screen at $-70^{\circ} \mathrm{C}$ for $6 \mathrm{~h}$.

Analysis of data. Only well-resolved fragments present in both template concentrations were scored. Data were scored independently by at least two people. The molecular size (in bp) of each fragment was determined by a linear regression of migration distances taken from single gels, and the presence or absence of each fragment of defined size was considered as an independent character. Fragments that migrated to the same position on these high-resolution sequence gels were considered to be from homologous loci.

Arbitrarily primed PCR characters were analysed using NTsYspc v. 1.8 (Rohlf, 1993). A similarity matrix was created using the Jaccard similarity coefficient (Sneath \& Sokal, 1973), which does not consider the joint absence of a marker as an indication of similarity. Clustering was done using the unweighted pair group arithmetic mean method (UPGMA) (Sneath \& Sokal, 1973). The resulting dendrogram was compared to the similarity matrix using cophenetic correlation (COPH and MXCOMP) 


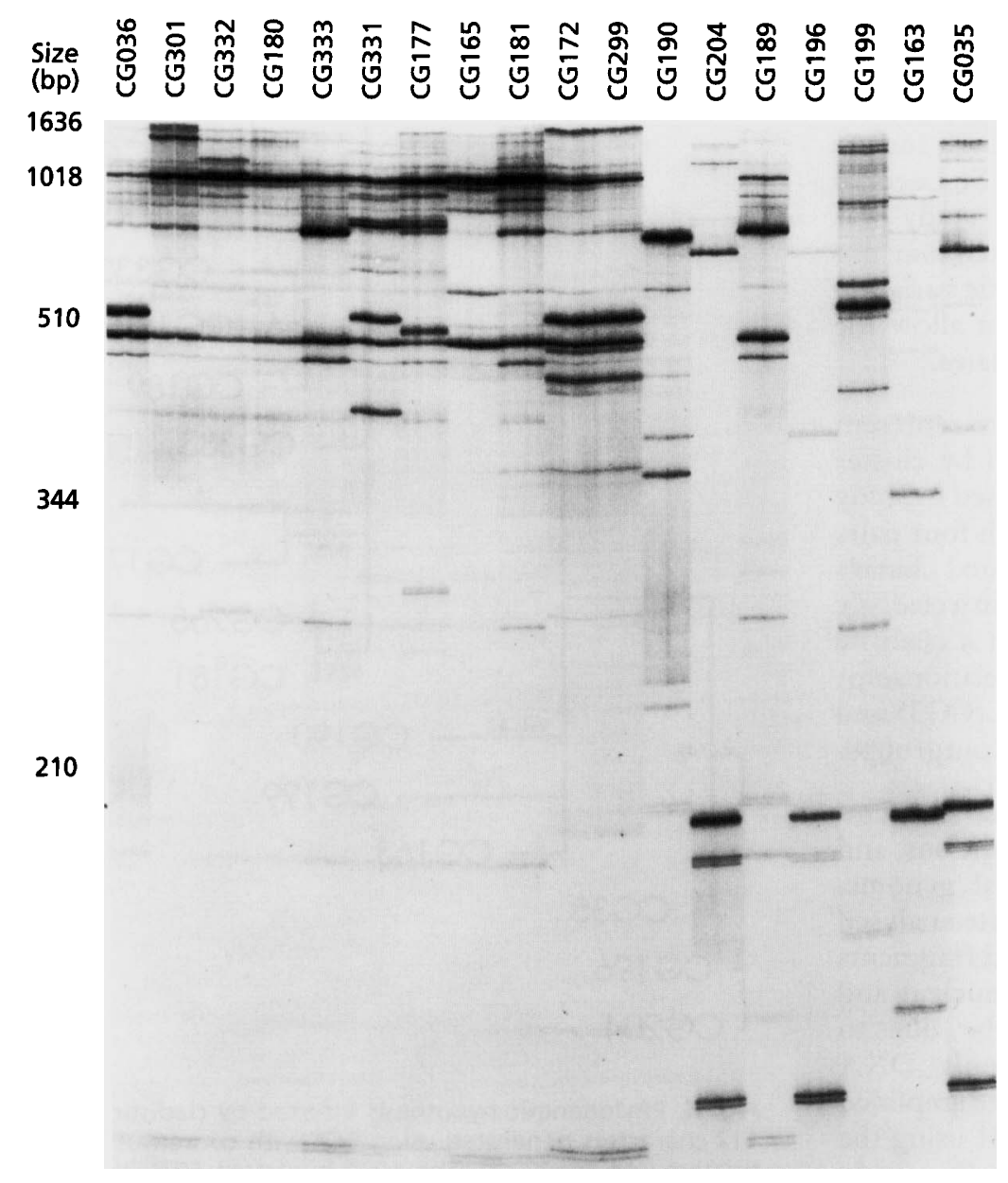

Fig. 3. Autoradiogram showing results of tRNA-PCR fingerprinting. Each strain appears in duplicate, with the first lane representing $10 \mathrm{ng}$ and the second $30 \mathrm{ng}$ of template DNA. The primer pair used was $\mathrm{AEU}+\mathrm{T} 3 \mathrm{~B}$. programs in NTSYS-pc. Phylogenetic hypotheses were inferred from the matrix of characters scored from tRNA-PCR amplifications using PAUP $v$. 3.1.1 (Swofford, 1993).

\section{RESULTS AND DISCUSSION}

Arbitrarily primed PCR proved to be an efficient method for detecting genetic variability of $P$. lilacinus isolates (Table 2). Isolates were assigned to P. lilacinus and other species on the basis of morphological characteristics. An example of the fingerprints obtained with two template concentrations, spanning a threefold concentration range, is shown in Fig. 1. The Jaccard similarity coefficients for pairwise comparisons of $28 \mathrm{P}$. lilacinus isolates varied from $84.3 \%$ to $7.6 \%$, with a mean of $63.5 \%$ (not shown). A study of 11 isoenzyme systems in a smaller number of isolates was unable to clearly identify intraspecific variation within P. lilacinus (M. S. Tigano-Milani and others, unpublished data). On the other hand, cluster analysis based on similarities computed from arbitrarily primed PCR markers showed a high level of variability among isolates morphologically classified as $P$. lilacinus species (Fig. 2). Isolate CG190 was almost as well separated from other $P$. lilacinus isolates as it was from a $P$. fumosoroseus isolate (CG204) used in this study as an outgroup, and displayed only $6.3 \%$ similarity to $P$. lilacinus isolates. We do not know why CG190, which is not unambiguous for morphological characterization, is so different from the remaining $P$. lilacinus isolates. Presumbly, the inaccuracy of morphological identification is the cause, since we extracted DNA repeatedly from this isolate and obtained the same fingerprints (not shown).

Although most studies have focused on the variability of entomopathogenic fungal isolates collected from hosts, here we detected variability in isolates of $P$. lilacinus obtained from soil samples. Isolates collected at the same time in nearby fields, for example CG308 and CG332, were distinct genotypes with only $66.6 \%$ similarity. In contrast, isolate CG308 is more similar ( $84.3 \%$ similarity) to isolate CG331, which was collected at a distant field. Regarding hosts, three isolates from nematodes (Meloidogyne sp.) from three Brazilian states (CG177, CG179 and CG180) were clustered at $67.9 \%$ similarity. However, the other two isolates from Meloidogyne, CG303 and CG172, from Peru and Italy, respectively, were well separated from each other and from the Brazilian isolates. In fact, cluster analysis did not support clearly defined phenetic groups within the sample of $P$. lilacinus isolates analysed. Furthermore, no correlation with geographical origin or host was detected even among the most similar isolates (Table 1, Fig. 2). Principal coordinates analysis of the matrix of Jaccard similarity coefficients confirmed the absence of clear groups within P. lilacinus isolates for 
which three main axes only accounted for $28.4 \%$ of the observed variability (not shown). The same high level of intra-specific variability was observed in a molecular marker analysis of other entomopathogenic fungi, such as Beauveria bassiana and Metarbizium anisopliae (St Leger et al., 1992; Fegan et al., 1993). The present study was conducted on a small number of isolates, which may not represent the entire range of intraspecific genetic variation of $P$. lilacinus. Study of a larger sample might allow the identification of closely related groups of isolates.

A subsample of $12 P$. lilacinus isolates, chosen to represent different levels of genetic similarity obtained by cluster analysis of arbitrarily primed PCR data, was used to study phylogenetic relationships. Amplification with four pairs of consensus tRNA gene primers generated binary characters in this subsample, which were used in a cladistic analysis. If this fungus is truly asexual, then a cladistic analysis will correctly infer phylogenetic relationships (Davis \& Nixon, 1992). P. fumosoroseus isolates (CG35 and CG204) were included in cladistic analysis as outgroups.

Given that imperfect matches between primer and template are possible under our amplification conditions, and that tRNA genes are divergent in a typical genome, several products were generated for each isolate analysed (Table 2). We expect that most of the amplified fragments represent various tRNA sequences from the nucleus and mitochondrion, but other products may be due to arbitrary amplification of unrelated loci; only DNA sequencing can resolve the genetic nature of the amplified products. However, a search of GenBank v. 81 using the sequences of the four tRNA primers used in this study revealed homology to eubacterial tRNAs as well as to fungal mitochondrial and nuclear tRNAs, and plant mitochondrial and chloroplast tRNAs (R. J. Honeycutt and others, unpublished). Reproducible tRNA fingerprints, obtained with the two template concentrations (spanning a twofold range), are shown in Fig. 3.

A Wagner tree, which allows free reversibility of character states, identified a monophyletic group containing all $P$. lilacinus isolates (Fig. 4), with the exception of CG190, in agreement with results obtained with arbitrarily primed PCR characters (not shown). The high amount of variability detected among $P$. lilacinus isolates, by arbitrarily primed PCR and tRNA-PCR, suggests that some of the amplification products, if further characterized by DNA sequencing, may provide information to construct diagnostic probes or primers for marker-assisted field studies.

Analysis of only three $P$. farinosus isolates indicated that this species encompasses a diverse group and may represent a species aggregate in which some isolates may be more closely related to other species of Paecilomyces. $P$. farinosus isolates were dispersed throughout the tree; CG189 was more closely related to $P$. lilacinus isolates, while CG196 was closer to $P$. fumosoroseus isolates. Perhaps analysis of a larger, more representative sample of isolates of both species would alter our understanding, but it is clear from results presented here that morphological

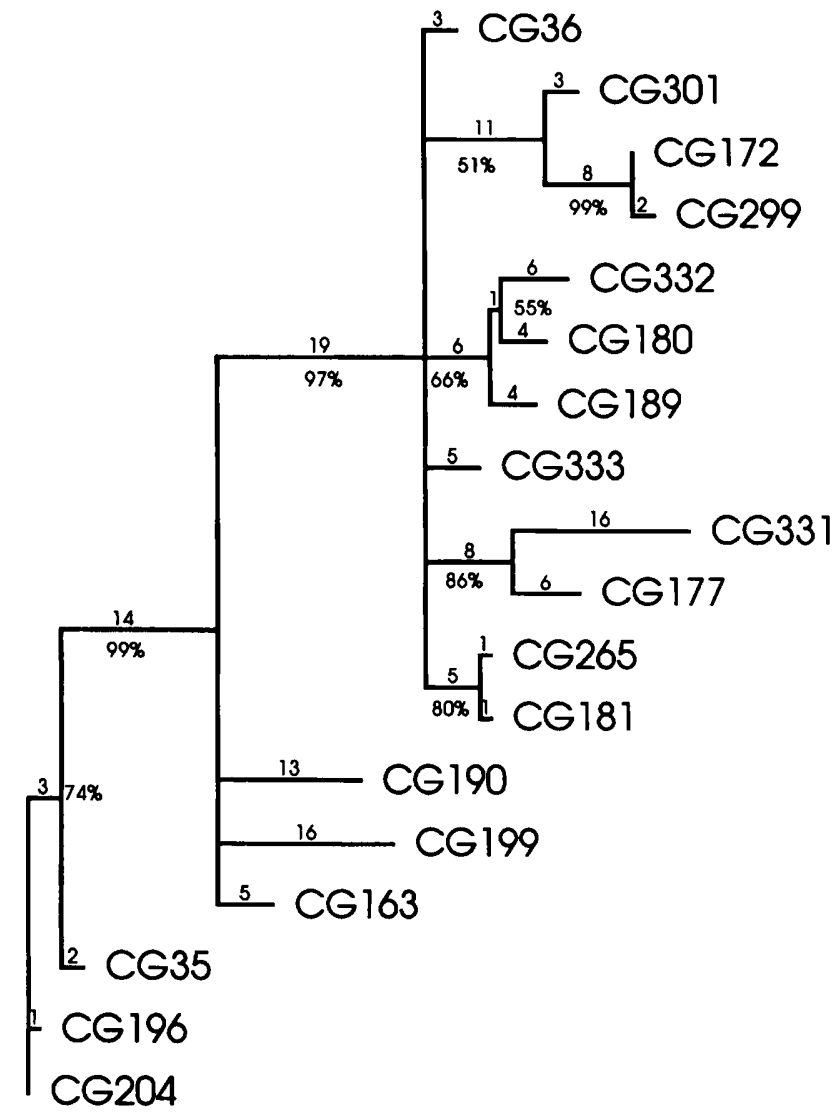

Fig. 4. Phylogenetic hypothesis inferred by cladistic analysis of 112 characters generated using PCR with consensus tRNA gene primers (see Methods). The 1000 bootstrap $50 \%$ majority rule tree was obtained through a bootstrapped branch-and-bound search in PAUP v. 3.1.1. (Swofford, 1993), in which tRNA characters were analysed as unordered binary characters (see Methods). The tree has been labelled with number of steps (above lines) and bootstrap consensus indices (below lines, shown as percentages). Rohlf's consistency index (Cl) for the bootstrap consensus tree was 0.925 .

characteristics of asexual structures are insufficient to yield a cohesive taxonomy of Paecilomyces, as we have seen in a similar analysis of $P$. fumosoroseus isolates (TiganoMilani et al., 1994b). The two isolates of $P$. fumosoroseus were closely related in the cladogram, in agreement with the monophyletic group identified by analysis of products amplified by tRNA consensus primers (Tigani-Milani et al., 1994a).The only isolate of P. amoenoroseus, CG163, was well separated from the other species (Fig. 4).

The present study showed that overall genetic variability revealed by DNA markers permits finer taxonomic resolution than do morphological characters of conidia, which are currently used in taxonomic studies of this genus. This is in agreement with results of other studies (Tigano-Milani et al., 1994a,b; Fegan et al., 1993). It is also not surprising that morphological differences, which in some cases may be caused by simple mutations (Kustersvan Someren et al., 1991), do not always accurately represent genetic variability of the genome, as has been 
observed with some isolates of $P$. farinosus. Classifications based on morphological criteria alone have had problems in identifying closely related species of other fungi, such as Aspergillus and Metarbizium (Kusters-van Someren et al., 1991; Fegan et al., 1993).

\section{ACKNOWLEDGEMENTS}

We thank R. Humber (USDA, Ithaca, NY) and R. D. G. Carneiro (EMBRAPA, Pelotas, RS, Brazil) for generously sending isolates and for isolate identification; R. J. Honeycutt (CIBR, La Jolla, CA) for critical review of this manuscript; and A. H. Milani, A. C. M. M. Gomes and R. Assis for their valuable help. This work was supported by a grant to M.S. T.M. from International Centre for Genetic Engineering and Biotechnology (ICGEB). M. S. T.M. was supported by the Brazilian National Research Council ( $\mathrm{CNPq})$ and Empresa Brasileira de Pesquisa Agropecuária (EMBRAPA). B.W.S.S. was partially supported by grants from the USDA, The International Consortium for Sugarcane Biotechnology and Pioneer Hi-Bred International (Des Moines, IA).

\section{REFERENCES}

Bidochka, M. J., McDonald, M. A., St Leger, R. J. \& Roberts, D. W. (1994). Differentiation of species and strains of entomopathogenic fungi by random amplification of polymorphic DNA (RAPD). Curr Genet 25, 107-113.

Carneiro, R. M. D. G. (1992). Princípios e tendências do controle biológico de nematóides com fungos nematófagos. Pesq Agropec Bras 27, 113-121.

Chase, A. R., Osborne, L. S. \& Ferguson, V. M. (1986). Selective isolation of the entomopathogenic fungi Beauveria bassiana and Metarbizium anisopliae from an artificial potting medium. Fla Entomol 69, 285-292.

Davis, J. I. \& Nixon, K. C. (1992). Populations, genetic variation, and the delimitation of phylogenetic species. Syst Biol 41, 421-435.

Domsch, K. H. \& Gams, W. (1980). Compendium of Soil Fungi, vol. 1, pp. 529-532. New York: Academic Press.

Fegan, M., Manners, J. M., Maclean, D. J., Irwin, J. A. G., Samuels, K. D. Z., Holdom, D. G. \& Li, D. P. (1993). Random amplified polymorphic DNA markers reveal a high degree of genetic diversity in the entomopathogenic fungus Metarbizium anisopliae var. anisopliae. J Gen Microbiol 139, 2075-2081.

Gupta, S. C., Leathers, T. D. \& Wicklow, D, T. (1993). Hydrolytic enzymes secreted by Paecilomyces lilacinus cultured on sclerotia of Aspergillus flavus. Appl Microbiol Biotechnol 39, 99-103.

Guthrie, P. A., Magill, R. A., Frederiksen, R. A. \& Odvody, G. N. (1992). Random amplified polymorphic DNA markers: a system for identifying and differentiating isolates of Colletotricbum graminicola. Phytopathology 82, 832-835.

Kusters-van Someren, M. A., Samson, R. A. \& Visser, J. (1991). The use of RFLP analysis in classification of the black Aspergilli: reinterpretation of the Aspergillus niger aggregate. Curr Genet 19, 21-26.

Lehmann, P. F., Lin, D. \& Lasker, B. A. (1992). Genotypic identification and characterization of species and strains within the genus Candida by using random amplified polymorphic DNA. J Clin Microbiol 30, 3249-3254.
Maniatis, T., Fritsch, E. \& Sambrook, J. (1982). Molecular Cloning: a Laboratory Manual. Cold Spring Harbor, NY: Cold Spring Harbor Laboratory.

McClelland, M., Peterson, C. \& Welsh, J. (1992). Length polymorphisms in tRNA intergenic spacers by using polymerase chain reaction to distinguish Streptococcal strains and species. $J$ Clin Microbiol 30, 1499-1504.

Rohlf, F. J. (1993). NTSYS-pc v. 1.8. Numerical Taxonomy and Multivariate Analaysis System. Setauket, NY: Applied Biostatistics Inc.

Rombach, M. C., Aguda, R. M., Shepard, B. M. \& Roberts, D. W. (1986). Infection of rice brown planthopper, Nilaparvata lugens (Homoptera: Delphacidae), by field application of entompathogenic hyphomycetes (Deuteromycotina). Environ Entomol 15, 1070-1073.

Samson, R. A. (1974). Paecilomyces and some allied hyphomycetes. Stud Mycol 6, 116 pp.

Sneath, P. H. A. \& Sokal, R. R. (1973). Numerical Taxonomy. San Francisco: Freeman.

Sobral, B. W. S. \& Honeycutt, R. J. (1993). High output genetic mapping in polyploids using PCR-generated markers. Theor Appl Genet 86, 105-112.

Sobral, B. W. S. \& Honeycutt, R. J. (1994). Genetics, plants, and PCR. In The Polymerase Chain Reaction, pp. 304-320. Edited by K. B. Mullis, F. Ferre \& R. A. Gibbs. Boston: Birkhauser.

St Leger, R. J., Allee, L. L., May, B., Staples, R. C. \& Roberts, D. W. (1992). World-wide distribution of genetic variation among Beauveria spp. Mycol Res 96, 1007-1015.

Swofford, D. L. (1993). PAUP: Pbylogenetic Analysis under Parsimony, Version 3.1.1. Champaign, Ill: Illinois Natural History Survey.

Tigano-Milani, M. S., Faria, M. R., Martins, I. \& Lecuona, R. E. (1993). Ocorrência de Beauveria bassiana (Bals.) Vuill., Metarbizium anisopliae (Metsch.) Sorok. e Paecilomyces sp. em solos de diferentes regiões do Brasil. Ann Soc Entomol Brasil 22, 391-393.

Tigano-Milani, M. S., Gomes, A. M. M. \& Sobral, B. W. S. (1994a). Genetic variability among Brazilian isolates of the entomopathogenic fungus Metarbizium anisopliae. J Invert Patbol (in press). Tigano-Milani, M. S., Honeycutt, R. J., Lacey, L. A., Assis, R., McClelland, M. \& Sobral, B. W. S. (1994b). Genetic variability of Paecilomyces fumosoroseus isolates revealed by molecular markers. $J$ Invert Patbol (in press).

Welsh, J. \& McClelland, M. (1990). Fingerprinting genomes using PCR with arbitrary primers. Nucleic Acids Res 18, 7213-7218.

Welsh, J. \& McClelland, M. (1991). Genomic fingerprintings produced by PCR with consensus tRNA gene primers. Nucleic Acids Res 19, 861-866.

Welsh, J., Pretzman, C., Postic, D., Saint Giron, I., Baranton, G. \& McClelland, M. (1992). Genomic fingerprinting by arbitrarily primed polymerase chain resolves Borrelia burgdorferi into three distinct phyletic groups. Int J Syst Bacteriol 42, 370-377.

Williams, J. G. K., Kubelik, A. R., Livak, K. J.., Rafalski, J. A. \& Tingey, S. V. (1990). DNA polymorphism amplified by arbitrary primers are useful as genetic markers. Nucleic Acids Res 18, 6531-6535.

Received 17 June 1994; revised 22 September 1994; accepted 6 October 1994. 